\title{
Chamanismo, relaciones interétnicas y revitalización cultural entre los Yawanawa ${ }^{1}$
}

\author{
Shamanism, Interethnic Relations and Cultural Revitalization \\ Among the Yawanawa
}

\author{
Virgilio de Almeida Gdowski Bomfim \\ Centro de Filosofia e Ciências Humanas, Departamento de Antropologia \\ Universidade Federal de Pernambuco, Brasil \\ ID ORCID: https://orcid.org/0000-0001-5705-389X \\ E-mail: abomfim.virgilio@gmail.com
}

Recepción: 08.12.2018

Aprobación: 01.12.2019

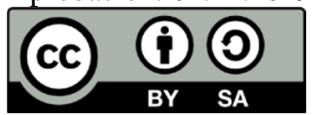

Resumen: Este artículo tiene como objetivo comprender la revitalización cultural Yawanawa a partir de una reflexión histórica y etnológica que centraliza en su narrativa el desarrollo de las relaciones entre indígenas y no indígenas. Este proceso empieza con la ocupación de las grandes cuencas hidrográficas amazónicas en busca del caucho y resigue los primeros contactos entre las etnias indígenas y la población migrante hasta la actualidad, incidiendo en la garantía de los derechos territoriales y la actuación de instituciones no gubernamentales en favor de los pueblos indígenas. A partir del Festival Yawa, celebración de la cultura Yawanawa que cuenta con la participación de alóctonos, el análisis discurre sobre la dialógica entre relaciones interétnicas, culturales e identitarias.

Palabras-clave: etnología amerindia, Yawanawa, chamanismo, etnicidad.

Abstract: This article aims to understand the Yawanawa cultural revitalization from an historical and ethnological reflection that focus on the development of the relations between the indigenous and non-indigenous. This process goes from the occupation of large Amazon basins in search of rubber and the first contacts between indigenous and migrant population to the actuality, with the guarantee of territorial rights and the work of non-governmental institutions in favor of indigenous

\footnotetext{
${ }^{1}$ El presente trabajo se llevó a cabo con el apoyo de la Coordinación de Mejoramiento del Personal de Educación Superior de Brasil (CAPES) y en colaboración con la Universidad de St. Andrews.
} 
peoples. From the Yawa Festival, an event celebrating the Yawanawa culture where there is nonindigenous participation, the analysis will focus on the dialogue between interethnic relations, culture, and identity.

Keywords: Amerindian ethnology, Yawanawa, shamanism, ethnicity.

\section{INTRODUCCIÓN: DESARROLLO HISTÓRICO DE LAS RELACIONES INTERÉTNICAS EN RÍO GREGÓRIO}

MAPA 1. TERRITORIO INDÍGENA DEL Río GREGÓRIO (AC)

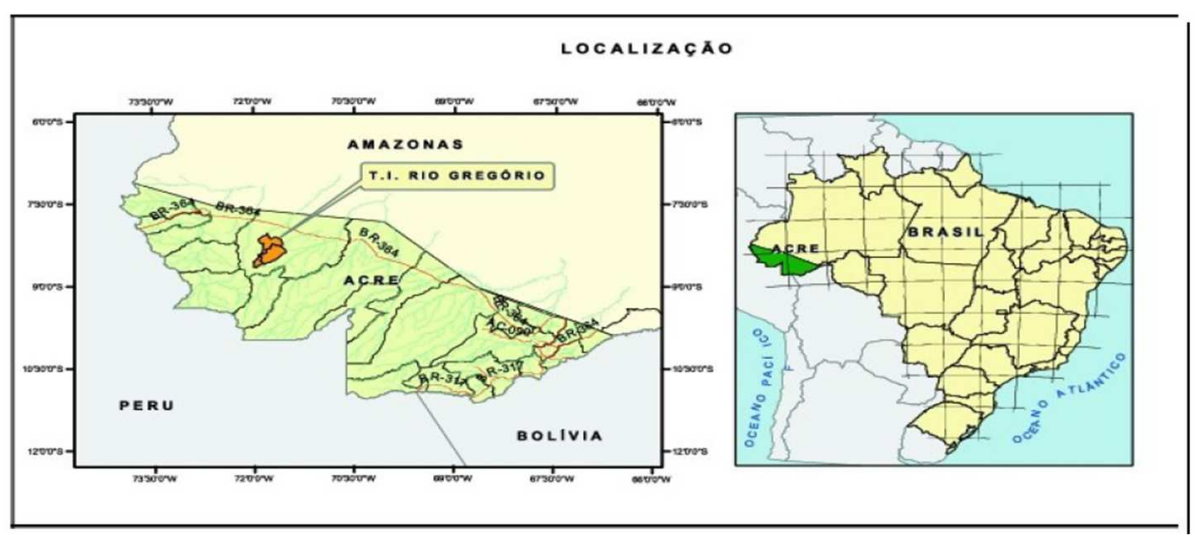

Fuente: Ribeiro, 2005.

Los Yawanawa pertenecen al tronco etnolingüístico Pano y, actualmente, viven en los márgenes del río Gregorio en el Estado de Acre, municipalidad de Tarauacá, con una población de alrededor de 950 habitantes. Reconocen esta región del Juruá como el área donde habitaron sus antepasados y hasta hace poco se mantenían solo de caza, pesca y agricultura. Con la llegada de los colonizadores del caucho y el establecimiento de relaciones duraderas con los mismos, la ocupación del territorio fijo en las cercanías de los seringales sustituyó una dinámica particular de ocupación del territorio y formación de grupos, regida por la disponibilidad de recursos, por guerras periódicas, por acusaciones de hechicería y por alianzas entre etnias. Como decían mis interlocutores, los Yawanawas puros, hijo de padre y madre Yawanawa, son pocos, casi ninguno. Históricamente la unidad étnica de los Yawanawa se compuso a partir de matrimonios endógenos, entre primos cruzados, entre pueblos aliados, como consecuencia del encarcelamiento de mujeres y niños después de conflictos bélicos con otras etnias 
como Kamanawa, Satanawa, Arara o Iskunawa (Carid Naveira, 1999; Erikson, 1993) y con otros colectivos de la zona.

La región del Juruá en que viven los Yawanawa concentra a varios pueblos Pano que optan por ocupar los interfluvios y las áreas de tierra firme selvática. Estos pueblos vivían de la agricultura, la caza y la pesca, hacían la guerra entre sí, como resultado del rompimiento de alianzas entre jefes, de acusaciones de brujería y envenenamiento y emboscadas para el secuestro de mujeres y niños. La llegada de los colonizadores del caucho ha introducido cambios en esos contextos interétnicos locales.

La trayectoria de la convivencia de los Yawanawa con los colonizadores se inicia con el boom del caucho y la llegada de los grandes grupos de caucheros a la región de la cuenca del Juruá en los últimos años del siglo XIX. La extensa región fluvial y forestal poblada por indígenas entre la bacía del Ucayali y Juruá fue dominada por la economía del caucho hasta la caída de su valor de exploración por los métodos empleados en la selva.

Relaciones interétnicas duraderas se desarrollarán allí, entre caucheros peruanos y brasileños y los pueblos indígenas. Surgieron variados contextos de convivencia entre los nuevos vecinos. Los caucheros a su llegada no sabían cómo vivir y aprovechar la selva, dado que venían de regiones de Brasil muy distintas de la Amazonia, a fin de mejorar sus condiciones de vida, trabajando para patrones que los explotaban frecuentemente.

La explotación del caucho nativo -Hevea brasiliensis- exigía vivir en la selva. Comida, herramientas, armas y medicamentos venían del barracão, tienda en las cercanías de las áreas de extracción, generalmente perteneciente al patrón y donde se compraba a crédito, o de los regateros, embarcaciones que navegaban vendiendo los productos entre estas nuevas poblaciones en los márgenes de los ríos.

Los encuentros de peruanos y brasileños con poblaciones indígenas fueron constantes y oscilaban entre la alianza y la guerra. Las etnias fueron diezmadas intencionadamente por presuponer que eran agresivas, por el surgimiento de conflictos a partir de la ocupación territorial y -como algunos relatos apuntan (Iglesias, 2008)- por los hurtos por parte de indígenas que visitaban las zonas ocupadas en busca de herramientas. Por otro lado, surgirán alianzas entre indígenas y patrones que, a cambio de herramientas, armas y alimentos, cazaban y enseñaban las sendas hacia árboles de caucho en la selva e incluso trabajaban como 
seringueiros ${ }^{2}$. La alianza con los alóctonos podía también garantizar la victoria de una etnia sobre otra con la que había un conflicto.

Aunque casi todo encuentro con poblaciones indígenas en Brasil es violento, de acuerdo con varias fuentes este no fue el caso de los Yawanawa. Con base a la investigación de Aquino y Iglesias (1992), May Ribeiro (2005) presenta un dato interesante sobre ese momento. Según los autores, los patrones Ângelo Ferreira y Felizardo Cerqueira eran conocidos por incorporar las poblaciones Kaxinawá, Yawanawá, Rununawa e Iskunawa a los trabajos del caucho a cambio de mercancías del barracão. A diferencia de la mayor parte de los patrones que hicieron guerras contra los indígenas en las regiones de asentamiento, Ângelo y Felizardo evitaban conflictos buscando relaciones amistosas. Así ambos ampliaron su área de influencia sobre los indígenas, incorporando a las familias al trabajo en el seringal. Tal y como hace constar Ribeiro (2005: 109) "Ângelo Ferreira também servia a outros patrões com seu contingente de índios civilizados na proteção dos seringueiros nordestinos contra os ataques e roubos por parte de índios ainda não contatados (especialmente los papavô을 e na abertura de estradas".

Entre los meses de julio y agosto, los Yawanawa se dedican a la siembra y a la pesca. La bajada de las lluvias y el aumento de la temperatura contribuyen a reducir las aguas del río Gregorio, período que coincide con la reproducción de los peces en la región. Lo cotidiano en estos meses es pescar y preparar la tierra para plantar. Fue en esa estación, en el quinquenio entre 1900 y 1905, cuando Ângelo Ferreira llegó por el Gregorio. Subió el río ya acompañado por varios indígenas de diferentes etnias, entre ellos había un katukina, mediador en este primer encuentro.

Según uno de los líderes actuales, Biraci Yawanawa, en ese encuentro el susodicho katukina pidió inmediatamente a los Yawanawa no empezar un conflicto, manifestando que Ângelo era una buena persona, diferente de otros forasteros de los cuales ya tenían noticias. El jefe Yawanawa respondió que sólo hablaba con aquel nawa si era capaz de compartir tabaco ${ }^{4}$. Ângelo recibió una

\footnotetext{
${ }^{2}$ Esta obra de Iglesias (2008) nos ofrece el desarrollo histórico de estas relaciones entre los Kaxinawa, etnia del mismo tronco lingüístico que los Yawanawa.

${ }^{3}$ Denominación utilizada en la región, mayoritariamente por los caucheros de los ríos Tarauacá y Jordán, para designar a los indios con los que no había contacto, bravos o salvajes, que saqueaban los seringales. Posiblemente, la mayor parte de esos papavô eran grupos hablantes de lenguas Pano, Nisinawa, Mastanawa, Binanawa y los Amauaca de las cuencas del Jordán y del Tarauacá (Iglesias, 2008).

${ }^{4}$ Nawa es un término polisémico, que adquiere su sentido de acuerdo con el referente y las circunstancias. Cuando junto a uno de los prefijos que dictan los nombres de las etnias Pano, adquieren el significado de pueblo, como en Yawanawa -pueblo del pecarí de labio blanco, Tayassu pecari-, pero desprovisto de cualquier sufijo puede ser entendido como foráneo. Se utiliza la voz nawa para referirse a los visitantes.
} 
bocanada de humo de tabaco y poco después hubo una gran cena. La historia continúa con Ângelo Ferreira recibiendo como regalo un niño que fue a la ciudad, aprendió portugués y una vez hecho adulto, se convirtió en el mediador de los Yawanawa con este patrón.

Años después de Ângêlo Ferreira vino Antonio Carioca, con quien los Yawanawa mantuvieron relaciones pacíficas por muchos años; eso sí, cada grupo en su orilla del río. La relación entre los Yawanawa y los patrones se perpetuó. Los indígenas se aplicaban tanto en abrir sendas hacia los árboles de caucho como en el cultivo de alimentos destinados al patrón. Estos servicios se pagaban con objetos tales como machetes, hachas, queroseno, rifles o sal. Según mis interlocutores, estos intercambios se hacían sólo entre los jefes y se consideraban justos.

Cuando muchos de los migrantes y patrones dejaron esta actividad a causa del éxito de las plantaciones desarrolladas en Malasia, fueron los Yawanawa y los Katukina los que pasaron a ocuparse de la extracción del caucho. Hasta entonces había poca participación del gobierno brasileño en esta región; es decir, en la intervención en la economía del caucho o en relación a los nativos que vivían allí. Fueron más de sesenta años de convivencia entre indígenas y caucheros, desarrollada por ellos mismos.

En el contexto de pérdida de valor económico del caucho, los Cariocas abandonaron la producción en el año 1968 y vendieron Caxinauás: el seringal pasó a otros dos patrones que finalmente abandonaron la producción. El último lo vendió en 1974 a la empresa Paranacre. En este momento, tanto los Yawanawa como otras etnias seguían sin el reconocimiento de sus territorios: la tierra era vendida con ellos viviendo en ella, teniendo que adaptarse a los nuevos vecinos. Historias similares ocurrieron con otros pueblos que habitaban en las regiones del Ucayali, Juruá y sus afluentes. Esta ocupación de la Amazonia se caracterizó por la empresa colonizadora (Gow, 1991).

Los Yawanawa, que antes vivían en relaciones amigables con los patrones, empezaron a ser reclutados para trabajos independientes como caucheros. Para ellos esa había sido la única opción para adquirir los bienes que tras medio siglo ya formaban parte de la vida cotidiana.

En la misma época llegan a la región grupos de misioneros para trabajar junto con los indígenas, ofreciendo su ayuda médica, catequizando y alfabetizando. Estaban en una aldea bajando el río y Tuin Kuru, el entonces jefe de los Yawanawa, los invitó a acercarse. La obra misionera traía la evangelización, los

\footnotetext{
${ }^{5}$ Así se llamaba el área ocupada por los patrones donde había los árboles de caucho.
} 
tratamientos asistenciales o la educación en portugués, entre otros aspectos. En la actualidad, el recuerdo de los misioneros de la MNTB -Missões Novas Tribos do Brasil- ha dejado una huella negativa: represión y prejuicio de que fueron objeto los indígenas.

Los interlocutores recuerdan que los misioneros solían criticar sus costumbres conyugales, su lengua, las guerras con otros pueblos, sus cantos y las técnicas de sanación de los chamanes. Según Biraci, los misioneros decían que todo eso era "del diablo: la lengua, las pinturas corporales y todo lo demás". En esos 18 años de actuación misionera, simultánea a la exploración de Paranacre, los indígenas no realizaban el saiti ${ }^{6}$. El prestigio y la ayuda de los chamanes desaparecieron y muchos sufrieron varias enfermedades llevadas por los inmigrantes.

Es importante mencionar que cuando los nuevos patrones pasan a exigir a los indígenas que trabajen como caucheros, surgen cambios en las relaciones sociales para la obtención de recursos, principalmente por la descentralización de las decisiones anteriormente tomadas por el jefe Yawanawa. Fragmentaban el grupo tanto la dispersión de las familias por el territorio en busca de los árboles de caucho como la pastoral misionera.

Mientras esto ocurría en la selva, en 1979 se fundó en la ciudad de Río Branco la Comissão Pró-Índio Acre-CPI-AC-, institución no gubernamental que empezó a denunciar a los patrones y que llevaba a los representantes de las etnias a los centros urbanos, ayudándolos a entrar en el emergente movimiento de lucha indígena por sus derechos. Entre las principales tareas desarrolladas por la CPI se encontraban el reconocimiento, la localización geográfica de los pueblos indígenas de la región y la organización sociopolítica por la garantía de sus territorios reconocidos por el Estado brasileño.

En 38 años de su actuación, la CPI promovió encuentros entre líderes para debates sobre cuestiones indígenas, creó los cursos para formar profesores y agentes de salud indígenas. Además, aseguró el registro escrito y audiovisual de los pueblos ubicados en Acre, y ayudó en la creación de cooperativas entre los indígenas con el propósito de garantizar la autonomía indígena en contraposición al continuo proceso histórico de imposición y explotación.

Terri Aquino, uno de los fundadores de la CPI-AC, estaba cartografiando la presencia de los pueblos indígenas en los afluentes del río Juruá cuando conoció el seringal Caxinauá. Una vez entró en contacto con los líderes locales, les

\footnotetext{
${ }^{6}$ Saiti y mariri se refieren al canto y la danza hecho por los Yawanawa en que en un gran círculo de personas con las manos entrelazadas un líder de canto entona las canciones que son acompañadas por todo el grupo que hace el círculo, incluso por los que están alrededor de la actividad.
} 
informó sobre la Fundação Nacional do Índio (FUNAI) y los derechos indígenas ${ }^{7}$. A parte de eso, fue él quien hizo una entrevista posteriormente utilizada en uno de los periódicos locales para denunciar los abusos de esta empresa y demostrar las condiciones en que los indígenas vivían.

\section{Fotografía 1. Pueblo YaWANAWA EN El SERINGAL CAXINAUÁ}

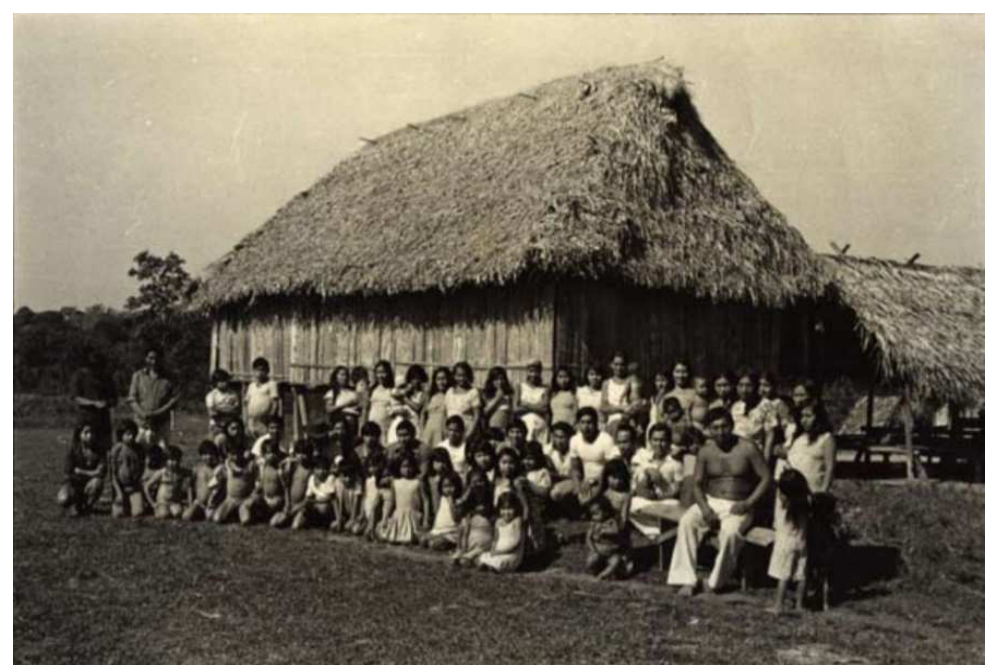

Fuente: Vinnya, Ochoa, Teixeira, 2006.

Fue por esas vías que algunos líderes indígenas supieron que la legislación brasileña era garante de sus derechos. Tuin Kuru, jefe Yawanawa de aquel entonces, fue el primero que salió de la selva para Brasilia con la intención de conocer otros líderes indígenas y aprender más sobre el mundo indígena. Cuando la convivencia con los centros urbanos se volvió más recurrente, Tuin Kuru envió a Biraci y a Sales para la ciudad.

Estos jóvenes Yawanawa continuaron la lucha por sus derechos participando en las reuniones del Conselho Indigenista Missionário (CIMI) y del CPI (Vinnya, Ochoa, Teixeira, 2006: 40). Se informaron sobre la legislación indígena y usaron el conocimiento adquirido. En el año 1983, el territorio indígena fue identificado por la FUNAI y con apoyo de las instituciones ya mencionadas, los Yawanawa, junto a los vecinos Katukina-Pano, lograron expulsar a los caucheros y a los patrones de sus territorios. El territorio fue demarcado en 1984.

\footnotetext{
${ }^{7}$ Creada en 1967, después de la extinción del Serviço de Proteção ao Índio (SPI), la Fundación Nacional del Indio (FUNAI) es el órgano indigenista del Estado brasileño responsable por los derechos de los pueblos indígenas en el territorio nacional.
} 
Los años ochenta fueron marcados por la intensificación de las relaciones entre los Yawanawa y otros pueblos. Por allí vendrán los cambios significativos respecto a las relaciones interétnicas desarrolladas en la actualidad.

\section{EL MOVIMIENTO INDÍGENA EN ACRE}

Estar libre de patrones implicaba una nueva cuestión: obtener los recursos ya incorporados a la cultura Yawanawa, que llegaban sólo a través del intercambio de servicios. Los Yawanawa, fuera ahora los patrones, perciben que la actividad del caucho desaparecía de la región y no podía ser la fuente de los recursos, ya que ellos mismos no lo podían producir.

Biraci y otros indígenas que se acercaron al CPI intentaron vivir en la ciudad y buscar profundizar su conocimiento sobre las cuestiones indígenas. Biraci trabajó junto al CPI y este fue el momento clave de su inserción en el movimiento indígena. Terri le ayudó en el conocimiento de la legislación brasileña, de la coyuntura relativa a los pueblos indígenas y le introdujo en las reuniones de líderes indígenas. Así, participó en el primer encuentro de líderes indígenas en el Acre y después de ese evento organizó, junto con Terri, la primera asamblea indígena de Acre.

El Oxford Committee for Famine Relief (OXFAM) también participó activamente en la institucionalización del movimiento indígena y en la fundación de varias cooperativas, trabajando durante varios años en colaboración con el CPI desde 1979- y con el CIMI, a partir de 1972. Conducidas por el principio de garantizar la sobrevivencia cultural dentro de las nuevas coyunturas, estas tres instituciones fueron decisivas en el devenir de muchos indígenas ubicados en Acre.

Con Terri, Biraci obtuvo el apoyo de la OXFAM logrando una donación de 7.000 dólares. Esa donación marca un nuevo período para los Yawanawa. Como otros indígenas, los Yawanawa pasaron a acceder a las asambleas y a estar en estrecha convivencia con las emergentes organizaciones indigenistas, momento que puede ser caracterizado por las estancias en la ciudad y el surgimiento de proyectos en favor del fortalecimiento de estas etnias.

En 1992 Biraci fue a Río de Janeiro para participar en la Conferencia de las Naciones Unidas para el Desarrollo y el Medio Ambiente, específicamente en un evento paralelo llamado Parlamento da Terra, que tenía presencia preponderante de indígenas. El evento en sí ya era una afirmación de los cambios en la relación entre los indígenas y la sociedad brasileña. 
Participando en dichas reuniones, Biraci asistió a un discurso del presidente de Aveda, empresa norteamericana que buscaba un pigmento natural para la producción de cosméticos. Lo que distinguía a esta empresa de las otras fue añadir a su producto el valor ecológico y natural, y también establecer contratos con las poblaciones llamadas tradicionales. Biraci habló con el presidente de Aveda y surgió un acuerdo que empezó con plantaciones de urucú, un pigmento natural ya utilizado por los indígenas. Con esta nueva posibilidad decidieron abrir una nueva aldea para vivir y dedicarse a esa actividad. Las familias que vivían en el seringal Caxinauá y otras que vivían en localidades cercanas se reunieron y empezaron a crear la nueva aldea: le dieron el nombre de Nova Esperança, afirmando en dicho topónimo la prospectiva que tenían para los próximos años. En este momento Biraci sustituyó a su tío Tuin Kuru en la jefatura. Sigue en esta función hasta hoy.

Con los desdoblamientos de la delimitación del territorio, de la concienciación de los derechos indígenas y de las nuevas posibilidades para la obtención de recursos provenientes del movimiento ecológico, los Yawanawa inician la revitalización de sus tradiciones. Varios indígenas han pasado a dedicarse a su cultura, registrando el conocimiento de los más viejos, regresando a las prácticas chamánicas y sus rituales.

En el año 2002, en Nova Esperança se estrenó el Festival Yawa, evento de celebración de la cultura Yawanawa. En la actualidad participan en ella personas de varios países interesadas en conocer las culturas indígenas, la Amazonia y, principalmente, las prácticas chamánicas yawanawa.

Inicialmente el Festival tenía pocos visitantes: la mayoría tenía algún compromiso con el gobierno de Acre y el movimiento indígena. En un par de años empezaron a participar en el Festival personas de otros estados brasileños y también de otros países. Este gran encuentro en Nova Esperança es el momento más expresivo de lo que los Yawanawa llaman el rescate, el renacimiento, o la revitalización de su cultura. La festividad celebra la prosperidad de los nuevos tiempos en oposición al período anterior, de conflictos, de dispersión de las familias, de dificultades y de opresión.

Ahora, después de aclarar las circunstancias históricas y las relaciones interétnicas, vamos a poder comprender la revitalización cultural. Del caucho a los acuerdos para producir materia prima. Actualmente, es la diferencia cultural la que mueve los acuerdos económicos y trae nuevos cambios a la aldea. 


\section{FESTIVAL YAWA: RELACIONES INTERÉTNICAS Y REVITALIZACIÓN CULTURAL}

Fotografía 2. SAITI EN EL PATIO CENTRAL DE NOVA ESPERANÇA

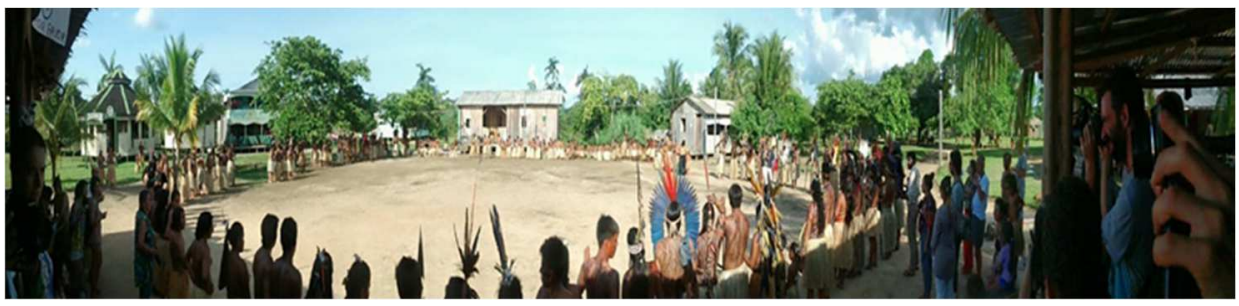

Fuente: Elaboración propia.

Mi trabajo de campo sobre la revitalización cultural duró tres meses y medio. Estuve en territorio indígena durante un mes en 2014 y luego por dos meses y medio en 2015. Dentro de ese período estaba incluido el Festival y pude acompañar a la organización de los indígenas. Actualmente sigo desarrollando también las temáticas de investigación entre más etnias de la región, especialmente los Katukina.

Antes del Festival, la organización en la aldea crea una dinámica específica de trabajos comunitarios: muchos salen de sus rutinas individuales para trabajar juntos y prepararse para la festividad. En las horas libres se dedican a hacer adornos de plumas y mimbre, practicar sus cantos o limpiar el patio juntos. Todas esas actividades están pensadas para la celebración.

La celebración tiene lugar el mes de octubre y dura cinco días. Llegan al territorio indígena varios grupos procedentes de los centros urbanos para ver $\mathrm{y}$, en algunos momentos, para participar de este evento. Los indígenas los ornamentan con las pinturas y les explican su significado. Algunos días, por la noche, hay rituales con romë y $u n i^{8}$. Hay momentos puntuales en que los líderes locales ofrecen discursos sobre la cultura indígena, destacando el proceso de revitalización de la cultura Yawanawa.

En los discursos, en el patio central, se recuerda el pasado cercano cuando no se hacían los kënes ${ }^{9}$ y los mariris. Se remonta a los tiempos cuando sus parien-

\footnotetext{
${ }^{8}$ Uni es el nombre en Yawanawa de la bebida conocida en algunos estudios científicos por el nombre de ayahuasca, denominación proveniente de la lengua quechua. La elaboración que presencié en Nova Esperança está compuesta de uni (Banisteriopsis Caapi) y kawa (Psychotria viridis). Romë potu es el tabaco macerado con cenizas de árboles. El uni, romë potu y una planta llamada muká son centrales en las prácticas dietéticas y de aprendizaje para la formación de un xinaya (orante).

${ }^{9}$ Traducido como "grafías", "diseños" son los patrones en las escamas de los peces, el que se mira en la ayahuasca y las pinturas corporales.
} 
tes estaban viviendo alejados unos de otros, olvidados de las tradiciones. Se hacen discursos sobre la época cuando no se reconocía al auténtico pueblo Yawanawa y cuando se los trataba como a inferiores, condenando sus tradiciones. Estos momentos generalmente anteceden o finalizan alguna actividad realizada en el Festival, ya sea el juego o el ritual nocturno.

Los juegos son las actividades que se organizan a partir de las relaciones de parentesco en la aldea -eso opone primos cruzados- y que hacen referencia a los animales del bosque y sus comportamientos. En paralelo a dicha actuación, ese momento de la fiesta acciona las relaciones de afinidad operantes en la aldea. El Festival cuenta también con paseos por el bosque para conocer la fauna y flora local y las ceremonias durante las cuales los visitantes-participantes pueden beber ayahuasca junto con los Yawanawa.

Según mis interlocutores, el Festival es "el momento en que el pueblo Yawanawa abre su casa a personas de fuera". Es el momento de hacer sus juegos, "juntar a los primos y vecinos", ornamentarse y reafirmar su historia. Un nuevo momento de prosperidad de las tradiciones de Yawanawa.

Dicen que ya se ha ido el tiempo en que los Yawanawa eran explotados y menospreciados por los forasteros. Cuentan que las personas que visitan la aldea hoy admiran a los indígenas y quieren aprender sobre sus tradiciones y todo lo que es gratificante para su pueblo.

La festividad integra los nuevos tiempos de los Yawanawa, definidos principalmente como un período de prosperidad cuando las nuevas generaciones ya crecen celebrando el valor de la cultura nativa y sus tradiciones. El pasado de conflictos, las epidemias y la sumisión vivenciada por muchos adultos son para los jóvenes apenas conocidos, ya que son niños nacidos en Nova Esperança. Desde el principio, bailar y cantar el saiti, interesarse por sus orígenes y beber uni forman parte de su vida. En los nuevos tiempos, los Yawanawa son admirados por los visitantes e inmortalizados por sus cámaras fotográficas. Comparten una fiesta que fortalece la tradición de su pueblo.

El Festival es también la autoafirmación de una identidad revitalizada, renacida, fruto de la historia y cultura Yawanawa. Al mismo tiempo se presenta así el ser Yawanawa. En los discursos durante el Festival se presenta la historia como un renacer cultural, de afirmación identitaria y política. En tanto que rito, en su dimensión simbólica, el Festival engloba a todos los Yawanawa y a los visitantes en la afirmación de esta realidad.

La participación de esos visitantes es una característica sobresaliente del Festival. Si a primera vista la etiqueta de etnoturismo puede añadir una apariencia 
específica al evento, la mayoría de los visitantes - así como los Yawanawa- entienden el Festival como algo muy distinto del turismo o una mera puesta en escena. Estos visitantes son también los colaboradores y compadres, nawa que auxilian en la revitalización cultural y con quienes hay amistad. Como se me dijo, "ya era costumbre nuestra recibir con reverencia a los vecinos desde los antiguos 'mariris"'.

Los visitantes llegan en barcos y son auxiliados por los indígenas que llevan sus equipajes a sus aposentos. Recientemente, un amigo de Biraci le ayudó a llevar a cabo la construcción de un conjunto de abrigos hechos con madera de la selva que los Yawanawa usan en varias construcciones. Son pequeñas casas, de planta rectangular, donde los visitantes arman sus hamacas y guardan sus equipajes. Cerca de esa construcción hay una área donde otros grupos llevan sus tiendas y hamacas, cerca de un pequeño río donde pueden bañarse. Este lugar se ubica a unos 600 metros del centro de actividades de la aldea.

Se puede enfatizar que la forma que la cultura y la tradición adquieren hoy en el saber nativo coincide con el inicio de varios cambios en el campo interétnico; en especial con la inclusión de nuevos segmentos de la sociedad compuestos de representantes de diferentes grupos de mentalidad ecológica y/o humanista. El Festival, como los antiguos encuentros interétnicos, es el propulsor del surgimiento de nuevas alianzas.

\section{AYAHUASCA EN LA REVITALIZACIÓN CULTURAL}

La motivación de los participantes del Festival surge casi invariablemente por el atractivo de estar en la selva y compartir las tradiciones ancestrales indígenas. Algunos ya conocen algunas tradiciones y medicinas de otros indígenas, lo realmente les motivó para conocer al pueblo Yawanawa. Había incluso una agencia de viajes, Dreamcatcher, que llevó a la aldea a un grupo de clientes.

En ese ambiente, favorable a los intercambios, los visitantes aprenden sobre ese ser indígena propagado por el Festival, para luego incorporar estas novedades aprendidas a sus propias vidas. Los visitantes y grupos ligados a los Yawanawa también aprenden los cantos; incluso ya existen vídeos en internet que muestran a los visitantes interpretando las canciones de los Yawanawa. En ese encuentro, un indígena puede entonces reconocerse a partir de la mirada de los visitantes. Son ellos los que reconocen en los indígenas la cultura originaria que vive en armonía con la naturaleza y sus recursos; lo que, de hecho, es verdad, si no destacamos los meandros semánticos que existen en esta traducción. En las rela- 
ciones con la sociedad que los circunda, los Yawanawa han hecho el paso del indio primitivo al caboclo, para entonces volver otra vez al indio, y a los ojos de algunos, a ser un bon sauvage.

Está claro que gran parte de los visitantes del Festival llega principalmente en grupos de personas asociadas a alguna institución ligada a la ayahuasca; la causa ecológica e indígena. Conocieron la celebración por participar en esos círculos. Además de las personas vinculadas al gobierno de Acre o al Ayuntamiento de Tarauacá, la mayoría estaba, de alguna forma, asociada a instituciones que utilizan Ayahuasca.

Esta bebida se difundió entre los mestizos y los caucheros que encontraron en el curanderismo y en ella el tratamiento alternativo de la selva. Las nuevas relaciones interétnicas introducen cambios en el espacio social; un mestizaje de etnias y sus culturas.

Como parte de ese proceso, la bebida y sus usos que ya circulaban por esos pueblos fueron reinterpretados. El uso de ayahuasca en Brasil estaba restringido a la región norteña y a los contextos sociales del caucho hasta fines de la década de los 70, período en que las instituciones sincréticas religiosas brasileñas, como la União do Vegetal y el Santo Daime, comenzaron su expansión en las principales capitales del país. En los centros urbanos brasileños, la ayahuasca conquistó un público distinto del anterior, mayoritariamente personas de clase media y alta, ligadas a los desdoblamientos de la contracultura, al arte, la psicología y las profesiones libres. El nuevo contexto añadió cambios en el entendimiento sobre la ayahuasca y la experiencia favoreciendo el modelado de la tradición a lo largo de los próximos años.

Por otro lado y simultáneamente, en Perú había más viajeros que conocían la bebida y los rituales, estableciendo las relaciones de aprendizaje, llevando este conocimiento a los países de origen e incluso al propio curandero, ampliando las redes de contactos. La ayahuasca amplió sus fronteras, fue interpretada a través de otras formas de comprensión de la experiencia ya codificadas en el ethos del segmento social en cuestión. En este momento, esta práctica se expande como un movimiento global, centralizado entre América y Europa, heterogéneo en sus formas de expresión. Surge en la era de la comunicación ampliando sus fronteras, sobre todo por los medios virtuales. Como se observa, en todo este proceso prevaleció la traducción cultural de la experiencia hasta el momento cuando las personas de grupos ya establecidos de tradiciones sincréticas hacen uso de la ayahuasca y buscan ir a la selva para conocer la tradición original. 
¿Por qué estas cuestiones son pertinentes en el estudio de las relaciones interétnicas y de la cultura? Desde su entrada en esos círculos, los Yawanawa han tenido un verdadero éxito más allá de sus tierras. Es sorprendente ver como sus rituales, ornamentos, canciones, juegos e imágenes salieron de sus aldeas y circulan por el mundo después de 16 años de Festival. La multiplicidad de factores que favorecieron la expansión no podría reducirse a la simple inserción de los indígenas en un mercado cultural, pues, al mismo tiempo, de forma paralela a ese proceso, viene ocurriendo principalmente la ampliación de sus colaboradores por amistad y por las causas en común.

La revitalización cultural empieza dentro de esas relaciones y sus circunstancias favorables, por medio de alianzas, amistades y proyectos que les dan forma y fuerza, tras la apertura del Festival y sus proyectos culturales. Demandas que surgen también de los otros integrantes de los círculos de mariri y de las tomas de ayahuasca. Se puede decir que en el Acre se produce una efervescencia cultural alrededor de esta bebida como el elemento de distinción y reconocimiento étnico, como el instrumento para garantizar la entrada de recursos en las aldeas a través de proyectos culturales.

Este movimiento que centraliza el uso ritual de la ayahuasca origina otras formas de beberla junto con otras etnias locales y el resto de la sociedad, hecho que viene trayendo recursos para las comunidades y legitimidad en un escenario de valorización de este conocimiento por segmentos de la sociedad global. La revitalización cultural de los pueblos en el Acre a través de la utilización de los vegetales recuerda la nueva ola de difusión del uso del peyote que, en el contexto de consolidación de la Native American Church y su utilización ceremonial, se difundió entre los pueblos indígenas -incluso los que no lo utilizaban anteriormente-, convirtiéndose en el elemento clave de la afirmación étnica.

En cuanto a la identidad en situaciones interétnicas, podemos recordar a Cardoso de Oliveira (2003) que propuso, inspirado por Fredrik Barth, una comprensión de la identidad étnica como aprehensión de sí en relación con otros. Ella es, por naturaleza, contrastiva, y por eso, cuando se afirma lo que es, se afirma también lo que no es.

En referencia a la iniciativa de los amerindios de registrar su tradición y promoverla, Carneiro da Cunha (2009) afirma que lo que denominamos cultura puede ser comprendida en dos aspectos: uno es su característica estructural, objeto de estudio antropológico; y el otro, la cultura es una dimensión autoreflexiva que se constituye en el contexto de las relaciones interétnicas. La expansión de las relaciones interétnicas se desarrolla ahora por lo cultural. Mediado por el uni 
y la cultura, el encuentro entre indígenas y ayahuasqueros puede ser entendido no sólo por el encuentro, sino también por los beneficios que cada uno encuentra.

Fotografía 3. TUIN KURU (VADÉ) MUESTRA SU ARTESANÍA A LOS VISITANTES EN NOVA ESPERANÇA

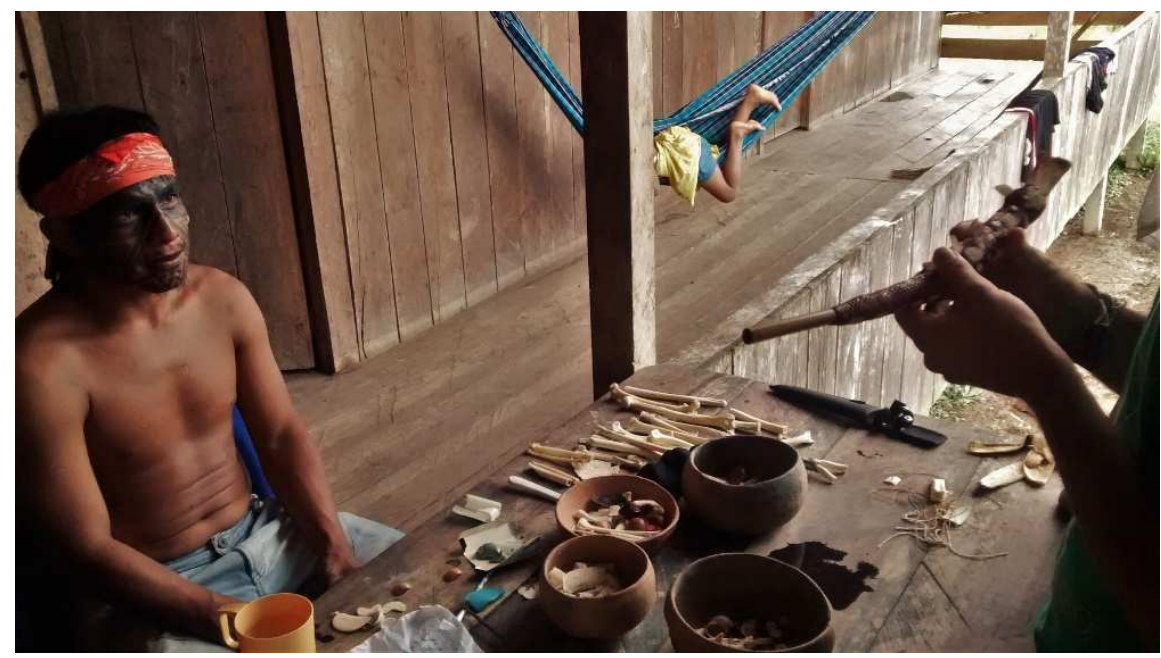

Fuente: elaboración propia.

Es cierto que en estos encuentros flota en el aire una imagen persistente y hegemónica sobre los pueblos indígenas: el indio ecologista. De hecho, como bien propuso Calavia (2006: 39), en una reflexión sobre el movimiento ecológico y las poblaciones tradicionales, estos "pueblos autóctonos o minorías étnicas o culturales de los cuatro rincones de la tierra son vistos como depositarios de saberes tradicionales respecto a su medio ambiente, y como alternativas éticas y técnicas al modelo económico moderno".

Una anamnesis de la idea de indígena ecologista nos llevará a las representaciones de Colón, Montaigne y Rosseau que en contraposición al tipo desarrollo de sus naciones, atribuyeron a los pueblos indígenas algo de pureza y ética. En sus pesquisas, Losonczy y Mesturini (2010: 11) confirman que en estos contextos "el misterio y el poder atribuidos a la ayahuasca se apoyan sobre una dialéctica particular de la identidad y de la alteridad, dialéctica que se construye gracias a la oposición binaria y emblemática entre lo Occidental y el Indígena”.

Esas circunstancias influyen en el entendimiento de sí, en el compromiso identitario comunitario e individual con la revitalización cultural. Hoy, los Yawanawa reciben personas de todo el mundo e, incluso, algunos de sus represen- 
tantes también viajan a las capitales de Brasil y de otros países llevando su tradición, representada por el ritual de uni, por los cantos y las danzas del saiti. Al mismo tiempo, sucede el repensar o el conocer mejor lo que se llama habitualmente lo blanco. En primer lugar fueron los caucheros y patrones, después los misioneros, el antropólogo, la FUNAI y las oenegés. Los nuevos grupos que surgen han añadido algunos nuevos elementos a esta amalgama de conceptos, idealizaciones y realidad.

Como sugiere Manuela Carneiro da Cunha "termos como índio, indígena, tribal, nativo, aborígene e negro são todos criações da metrópole, são frutos do encontro colonial. E embora tenham sido genéricos e artificiais ao serem criados, esses termos foram progressivamente habitados por gente de carne e osso" (2009: 278). Esta gente de carne y hueso no ignora el papel que se les atribuye y el valor para ellos en el contexto interétnico en análisis.

$\mathrm{Al}$ igual que los indígenas, esos visitantes y colaboradores pasan a conocer a otro indio, real y del que apenas existe una imagen en las grandes ciudades, al darse una representación del indígena de un pasado lejano, del tiempo de la conquista, sin ninguna relación con la realidad vivida por esos pueblos en la actualidad.

\section{CULTURA E IDENTIDAD EN PERSPECTIVA}

$\mathrm{Si}$, como recuerda Sahlins, la antropología se ocupó inicialmente de una "arqueología del viviente", buscando registrar las culturas "tradicionales" antes del fin irremediable por el avance de la civilización, hoy está en otra dirección (Sahlins, 1999). Los "indígenas" están lejos de desaparecer. Al contrario, a pesar de los conflictos, muchos pueblos crecen demográficamente y se comprometen a la defensa de sus derechos.

Por desarrollarse simultáneamente a las circunstancias procesuales de la cultura y de la historia, las dinámicas interétnicas solo pueden ser comprendidas junto con un análisis cultural. En esta pesquisa opté por la relativización del análisis antropológico propuesto por Wagner (1975) y, posteriormente, por la etnología amerindia brasileña (Viveiros de Castro, 2002a), de que la cultura es el punto de vista y el objetivo del antropólogo. Empecé por el reconocimiento de que la propia antropología es un hecho cultural y de que la construcción de la veracidad del conocimiento antropológico, los análisis y las generalizaciones ya son, en sí mismos, cultura.

Para Wagner, un investigador tiene que abdicar de la pretendida objetividad absoluta para ir hacia una objetividad relativa en que reconoce su propia cultura 
en la construcción del conocimiento. Esto es fundamental para tener en cuenta que estos procesos culturales son comprendidos por nuestros puntos de vista y además debemos hacer presente la meta-reflexión. Observando el proceso cultural como simétrico y estructuralmente dinámico, podemos comprender los resultados de estos encuentros, observando las dinámicas interétnicas y sus circunstancias.

El Americano cien por cien de Ralph Linton es una alegoría que pone en evidencia la relación entre identidad y cultura, considerando justamente los desarrollos de las relaciones interétnicas. Puede enseñar que la cultura, la forma en la que la concebimos, sólo puede ser comprendida si se considera su inherente dinámica y transformación en el tiempo. Estos estadounidenses, descendientes de africanos, indígenas e inmigrantes europeos de diversos países, usan innumerables objetos de otros tiempos y sociedades, objetos materiales e ideas y aún se constituyen como norteamericanos en su propia cultura.

Entre los Yawanawa se recuerda de quién se desciende. Se tienen presente los conocimientos que son originarios de otras etnias cercanas, lo que no hace que no dejen de ser yawanawas. Cantos, herramientas y técnicas de pueblos vecinos, aliados o enemigos, pasados o presentes, pueden formar parte de su cultura. Comprender las culturas por esas dinámicas aclara los procesos de apropiación material, técnica y simbólica. Son adquisiciones regidas por algo preexistente, también en transformación, lo que llamamos conceptualmente de lógica nativa.

Un argumento interesante de contraste con estos datos empíricos está en Sahlins y su idea de indigenización de la modernidad. Dicho autor afirma que:

Even if coercively imposed, external practices and relationships are necessarily brought into value-determining associations with native categories. In the upshot, they acquire indigenous logics, intelligibilities and effects. Although in theory structure is supposed to be a concept antithetical to history and agency, in practice it is what gives historical substance to a people's culture and independent grounds to their action. Without cultural order there is neither history or agency. (1999: 9)

En ese sentido, la indigenización de la modernidad ocurrió entre todos los pueblos. Adaptar algo nuevo de las más variadas maneras a una lógica nativa no puede ser algo exclusivo de un grupo. En la indigenización sucede, paradójicamente, una adaptación de la lógica nativa y a la lógica nativa. Estas ya existían incluso antes del caucho, comprobado por la presencia de grupos Arawak, Pano y Tucana en la región. Esta problemática que relaciona a los indígenas, la lógica de mercado y el concepto de cultura, que pone la introducción de elementos del modus operandi hegemónico como causa de la pérdida de la cultura, favoreció el 
desequilibrio en las relaciones con el Estado, legitimador jurídico de las identidades y territorios.

El saiti y los juegos ya existían entre los Yawanawa, eran momentos de reafirmación de alianzas con sus vecinos, matrimonios e intercambios de conocimientos. Y si los cantos del saiti yawanawa son de varios orígenes, siendo algunos reconocidos como Katukina, Kaxinawa y Iskunawa, ni por eso dejan de ser considerados por la tradición Yawanawa. Actualmente, las alianzas, los festivales y las visitas a centros urbanos dinamizan este campo añadiendo nuevos cantos e instrumentos; esto es, nuevos nawa.

Estos aliados están incorporados a la sociedad Yawanawa por contextos que remiten al espacio de socialización anterior, los mariris que, según los indígenas, dinamizan las relaciones interétnicas de la región. Desde el punto de vista etnológico (Seeger, Matta, Viveiros de Castro, 1979; Viveiros de Castro, 2002b), las cosmologías y la sociabilidad de los pueblos de las tierras bajas están elaboradas en estrecho vínculo con sus comprensiones de corporalidad y alteridad.

Para algunos Yawanawa, estas fiestas no están muy lejos de los encuentros que reunían solo a los pueblos de la región. Es un espacio social equivalente que acciona los vínculos con la alteridad y es eficaz en el manejo de las relaciones con los otros en el contexto interétnico. Los conocimientos y técnicas chamánicos, que tratan de la relación con los yuxin, los espíritus que habitan el bosque y que interfieren en la vida de los humanos, son actividades que involucran a foráneos que están influenciando en su actuación la alteridad vertical con la cual también se debe buscar el equilibrio (Pérez Gil, 1999; Lima 2000). Antes del Festival, un jefe planeaba hacer una dieta con toda su familia, para proteger a sus parientes de ataques de yuxin en un momento más vulnerable.

Al mismo tiempo que la indigenización de la modernidad ocurre la modernización de la indianidad; esto es, los principios locales traducen los nuevos elementos simbólicos y materiales según su lógica, mientras tanto esos nuevos elementos simbólicos, materiales y de convivencia con el otro también transforman los principios.

Si organizar buenas cacerías, garantizar el éxito del grupo, la armonía en los hogares, el territorio y la distribución de recursos ya era una característica del shaneihu -o jefe -, la interacción con los nuevos aliados y los proyectos no deja de integrarse a ese proceso que se encuentra ya en marcha. Así, añadir al acervo nawa las relaciones kuka-pia-tío materno-sobrino- es otro ejemplo.

La cuenca amazónica y sus afluentes fueron y siguen siendo caminos de comunicaciones entre individuos y grupos étnicos y sus innovaciones técnicas, 
invenciones, conocimientos botánicos y cosmologías. Lo alóctono está incorporado a una lógica nativa dinámica, así como sucede lo contrario, los entendimientos se transforman, especialmente en el contexto evidenciado anteriormente que nos presenta nuevos horizontes para esta relación con los indígenas, a través del Festival y de la ayahuasca.

Ciertamente, el núcleo de la cultura de muchos pueblos radica en la adquisición de nuevas prácticas surgidas de relaciones con los vecinos. El ejemplo del americano cien por cien de Linton es eficaz para mostrar que la identidad étnica es más compleja que el uso o no de instrumentos, objetos y técnicas provenientes de otros pueblos, incluso de los que ya no existen.

Indianidad y modernidad utilizados aquí ejemplifican un caso empírico de un proceso que existe en otros tiempos y contextos. La posibilidad reflexiva de la cultura siempre existió, pero se realiza en diferentes contextos y la delineación de esa característica se modela con la intensificación de las relaciones entre poblaciones tradicionales y el Estado, oenegés y el comercio (Comaroff, Comaroff, 2009).

Todavia, la idea de etnoturismo, como constaba en sitios de divulgación del Festival, puede a primer vistazo reducirse a un evento escénico, de indígenas que se preparan para recibir a los visitantes. Esta pesquisa constató que hay una reorganización local buscando vitalizar un ethos Yawanawa a través de esos modos de sociabilidad, lo que incluye también a esos otros como colaboradores y parte esencial de su renacimiento cultural.

En el ámbito interétnico, los eventos de este tipo involucran relaciones sociales duraderas. En las dinámicas internas pueden representar desde mejoramiento en la asistencia médica, de infraestructura y de recursos a procesos como la revitalización de prácticas chamánicas e interacciones con influencias de fuerzas espirituales; un universo amplio y bien complejo en el cual me detuve en lo que pude comprender durante la pesquisa.

En la medida en que la cultura como fenómeno no es estática, la reinvención es intrínseca a la cultura. Para pensar en la revitalización, fue necesario situarla históricamente, comprender la inserción yawanawa en la articulación política indígena en un contexto de cambios para los indígenas, de visibilidad internacional.

El momento en que se hacen nuevos ornamentos de plumas y se rescata, revitaliza y retoma la cultura, ya es un auténtico resultado cultural. Es como el Renacimiento europeo, época en que se tornó la mirada a los orígenes ancestrales griegos y romanos. Para eso estaban situados en su tiempo como referentes y tuvo un marcado sentido en la mentalidad, en la ética, en la estética y en todas sus 
dimensiones sociales. No fue considerado ficticio: se le consideraba una revolución.

Sobre la mercantilización de la cultura, los Comaroff (2009), al buscar comprender la generación de rendimientos a partir de la tradición entre las poblaciones víctimas del colonialismo, perciben que la relación con el mercado no se limita a la venta: también influye en la identidad y en el sentido de colectividad. La mercantilización impacta en la construcción de la subjetividad, así como en los procesos identitarios, generando en los casos citados por los autores el compromiso con la tradición y con la cultura, específicamente en sus aspectos reflexivos y relacionales, como propone Carneiro da Cunha (2009), la "cultura" entre comillas.

La producción de pulseras, pendientes y tantos otros artículos con nuevas formas de kënes en estos proyectos fue estimulada por la mercantilización e incluso reorganiza la vida cotidiana de algunos y la sociabilidad local. Los autores apuntan que ese proceso tiene terreno fértil en las políticas de identidad recientes. En el caso indígena, a partir de organizaciones a nivel global que insertan esas poblaciones en una coyuntura sociocultural global en marcha de la mercantilización identitaria-cultural, de la producción y de la afirmación de la diferencia. En estos términos, la entrada de los Yawanawa en el etnoturismo se asemeja a los Maori (Comaroff, Comaroff 2009: 65); actúa tambíen reforzando una natividad material y cultural.

De alguna manera, mercantilizar la cultura tiene que ser comprendido a partir de la realidad indígena y de las formas internas de organización. De eso se puede deducir que la interacción con esta sociedad que los rodea, la adquisición de bienes foráneos y la inserción en el mercado como productores no implica la pérdida o el fin de la cultura. Al contrario, puede reforzar y adaptar lógicas internas ya existentes e incluso favorecer el desarrollo y el florecimiento, y no supone la extinción de una cultura. Por fin, quiero terminar con un argumento de Sahlins que refleja bien lo que este trabajo ejemplifica con los Yawanawa y la mercantilización de la cultura:

If it is true that commodification is the death of authentic culture, how come Americans still have one? Or if you think they do not, consider that the following things are produced or reproduced there as commodities and distributed through market relations: Beethoven's Fifth Symphony, sons and daughters of Americans adopted from Mexico, the Bible (or word of God). (1999: 7) 


\section{CONSIDERACIONES FINALES}

Quisiera evidenciar en este artículo que la revitalización es, en sí mismo, un proceso cultural. Un análisis histórico de las relaciones interétnicas, percibidas en sus circunstancias, me condujo a una reflexión sobre la dinámica de la cultura y de la lógica nativa.

Busqué también contribuir con lo que en la actualidad sigue siendo un foco de atención de varios investigadores: la elaboración de una narrativa antropológica que reconozca en la escritura etnográfica los matices de la traducción, los puentes semánticos que se construyen en el desarrollo de la argumentación. Reconocer que el conocimiento antropológico es también un saber nativo cuestiona no sólo los conceptos y su adecuación a los casos empíricos, sino la naturaleza propia de esos conceptos como herramientas culturalmente construidas.

Reconocer esas relaciones interétnicas como encuentro simétrico (Latour, 1994) de nativos permite un análisis dialógico de los procesos de cambio cultural, obviamente inscritos en relaciones desiguales de poder y que resultan en transformaciones para ambos actores. Cada uno en sus especificidades y circunstancias.

Parece que los líderes y chamanes Yawanawa son conscientes de algo que Ortega y Gasset (1966: 322) nos había dicho: que "Yo soy yo y mi circunstancia, y si no la salvo a ella no me salvo yo".

\section{BIBLIOGRAFÍA}

Aquino, T. V., Iglesias, M. P. (1992). Kaxinawá do Rio Jordão, História, Território, Economia e Desenvolvimento Sustentado. Rio Branco, Brasil: CPI-AC.

Calavia, O. S. (2006). El índio ecológico. Diálogos a través del espejo. Revista de occidente, (298), pp. 27-42.

Carid Naveira, M. A. (1999). Yawanawa: da guerra a festa [tesis de maestría]. Santa Catarina, Brasil: Universidade Federal de Santa Catarina.

Comaroff, J. L., Comaroff J. (2009). Ethnicity, Inc. Chicago, IL: University of Chicago Press. https://doi.org/10.7208/chicago/9780226114736.001.0001

Carneiro da Cunha, M. (2009). Cultura com aspas. São Paulo, Brasil: Consacnaify.

Erikson, P. (1993). Une Nébuleuse compacte: le macro-ensemble pano. L'Homme, 33(126-128), pp. 45-58. https://doi.org/10.3406/hom.1993.369628

Gow, P. (1991). Of Mixed Blood: Kinship and History in Peruvian Amazonia. Oxford, Reino Unido: Claredon Press. 
Iglesias, M. P. (2008) Os Kaxinawá de Felizardo: correrias, trabalho e civilização no Alto Juruá [tesis de doctorado]. Rio de Janeiro, Brasil: Universidade Federal do Rio de Janeiro.

Latour, B. (1994) Jamais fomos modernos: ensaio de anrropologia simétrica. Rio de Janeiro, Brasil: Editora 34.

Lima, E. C. (2000). Com os olhos da serpente: homens, animais e espíritos nas concepções Katukina sobre a natureza [tesis de doctorado]. São Paulo, Brasil: Universidade de São Paulo.

Losonczy, A., Mesturini, S. (2010) Por que a ayahuasca? Da internacionalização de uma prática ritual ameríndia. Anuário Antropológico, (1), pp. 9-30.

Oliveira, R. C. (2003). Identidade étnica, identificação e manipulação. Sociedade e Cultura, 6(2), pp. 117-131.

Ortega y Gasset, J. (1966). Meditaciones del Quijote. En J. Ortega y Gasset, Obras Completas de José Ortega y Gasset (7ª ed., Tomo 1). Madrid, España: Revista Occidente.

Pérez Gil, L. (1999). Pelos caminhos do Yuve: conhecimento, cura e poder no xamanismo Yawanawa [tesis de maestria]. Santa Catarina, Brasil: Universidade Federal de Santa Catarina.

Ribeiro. M. W. T. (2005). Uma tribo vai ao mercado - Os Yawanawa: sujeitos ou objetos do processo? [tesis de doctorado]. Rio de Janeiro, Brasil: Universidade Federal Rural do Rio de Janeiro.

Sahlins, M. (1999). Two or three things That I know about Culture. The Journal of the Royal Anthropological Institute, 5(3), pp. 399-421. https://doi.org/10.2307/2661275

Seeger, A., Matta, R. da, Viveiros de Castro, E. (1979). A construção da pessoa nas sociedades indígenas brasileiras. Boletim do Museu Nacional, (32), pp. 2-19.

Vinnya, A. L., Ochoa, M. L. P., Teixeira, G. A. (eds.). (2006). Costumes e Tradições do Povo Yawanawá. Rio Branco, Brasil: Comissão Pró-Índio do Acre, Organização dos Professores Indígenas do Acre.

Viveiros de Castro, E. (2002a). O nativo relativo. Mana, 8(1), pp. 113-148. https://doi.org/10.1590/S0104-93132002000100005

Viveiros de Castro, E. (2002b). Perspectivismo e Multinaturalismo na América indígena En E. Viveiros de Castro (ed.), A inconstância da alma selvagem (pp. 225-254). São Paulo, Brasil: Consacnaify.

Wagner, R. (1975). The invention of culture. Chicago, IL: University of Chicago Press. 